\title{
ATIVIDADE DE NUCLEAÇÃO DE GELO E DENSIDADE POPULACIONAL DO PATÓGENO PODEM SER FATORES QUE CONTRIBUEM PARA O PROGRESSO DA DOENÇA MANCHA BRANCA DO MILHO
}

\author{
Kátia Real Rocha ${ }^{1}$ \\ Walter Fernandes Meirelles ${ }^{2}$ \\ Nelson Barros Colauto ${ }^{3}$ \\ Giani Andrea Linde ${ }^{3}$ \\ Thiago Teodoro Santana ${ }^{3}$ \\ Luzia Doretto Paccola-Meirelles ${ }^{1,3}$
}

ROCHA, K. R.; MEIRELlES, W. F.; COLAUTO, N. B.; LINDE, G. A.; SANTANA, T. T.; PACCOLA-MEIRELLES, L. D. Atividade de nucleação de gelo e densidade populacional do patógeno podem ser fatores que contribuem para o progresso da doença Mancha Branca do Milho. Arq. Ciênc. Vet. Zool. UNIPAR, Umuarama, v. 22, n. 4, p. 157-164, out./dez. 2019.

\begin{abstract}
RESUMO: A Mancha Branca do Milho (MBM) é uma doença foliar que tem causado perdas apreciáveis, tanto qualitativas como quantitativas para a produção de milho. Seu agente etiológico, a Pantoea ananatis, é uma bactéria epifítica, Gram-negativa formadora de colônia amarela, capaz de formar gelo, mesmo em ambiente tropical (ice nucleation activity - INA). Este estudo teve por objetivo caracterizar isolados de $P$. ananatis quanto à atividade INA e avaliar o efeito da densidade bacteriana na expressão do fenótipo INA e no processo de desenvolvimento da doença. O agente patogênico foi isolado de lesões iniciais da doença, as anasarcas, e avaliado quanto à expressão do fenótipo INA em diferentes concentrações bacterianas. O mesmo foi feito com isolados epifíticos obtidos da superfície foliar de plantas de milho sadias. Dos 24 isolados bacterianos estudados, apenas 13 apresentaram o fenótipo INA+. A expressão deste fenótipo foi dependente da densidade celular. Isolados INA+ e INA ${ }^{-}$foram inoculados em folhas destacadas e em plantas da cultivar HS200 a campo, em diferentes concentrações do inóculo. Nenhum isolado INA ${ }^{-}$reproduziu sintomas em laboratório. Dos cinco isolados INA+ somente um deles reproduziu sintomas em laboratório. Em campo o isolado INA+ foi capaz de promover lesões em todas as concentrações avaliadas. Conclui-se que a atividade de nucleação de gelo pela bactéria $P$. ananatis é dependente da linhagem e da densidade bacteriana e este fenômeno pode estar envolvido no desenvolvimento dos sintomas da MBM.
\end{abstract}

PALAVRAS-CHAVE: INA. Pantoea ananatis. Phaeosphaeria maydis. Zea mays.

\section{ICE NUCLEATION ACTIVITY AND DENSITY OF THE PATHOGEN POPULATION MAY BE FACTORS THAT CONTRIBUTE TO THE PROGRESSION OF MAIZE WHITE SPOT DISEASE}

\begin{abstract}
Maize White Spot Disease is a leaf disease that has caused considerable losses, both qualitative and quantitative for corn production. Its etiologic agent, Pantoea ananatis, is an epiphytic, Gram-negative, yellow colony-forming bacterium, capable of forming ice, even in tropical environments at temperatures where this normally does not occur (Ice Nucleation Activity - INA). This study aimed at characterizing $P$. ananatis isolates in terms of INA activity and evaluating the effect of bacterial density on the expression of the INA phenotype and on the disease development process. The pathogen was isolated from the initial lesions of the disease, the anasarcas, and were evaluated for the expression of the INA phenotype in different bacterial concentrations. The same procedure was performed on epiphytic isolates obtained from the leaf surface of healthy maize plants. From the 24 bacterial isolates studied, only 13 presented the INA+ phenotype. The expression of this phenotype is dependent on cell density. INA+ and INA- isolates were inoculated on detached leaves and on plants of cultivar HS200 in the field, in different concentrations of the inoculum. No INA ${ }^{-}$isolates reproduced symptoms in the laboratory. From the five INA+ isolates, only one of them reproduced symptoms in the laboratory. In the field, the INA+ isolate was able to promote lesions in all concentrations evaluated. It can be concluded that the ice nucleation activity by $P$. ananatis is dependent on the strain and bacterial density and this phenomenon may be involved in the development of Maize White Spot Disease symptoms.
\end{abstract}

KEYWORDS: INA. Pantoea ananatis. Phaeosphaeria maydis. Zea mays.

\footnotetext{
DOI: 10.25110 /arqvet.v22i4.2019.7935

${ }^{1}$ Universidade Estadual de Londrina, Londrina-PR, CCB - Departamento de Biologia Geral -Bacharelado em Ciências Biológicas;

${ }^{2}$ Empresa Brasileira de Pesquisa Agropecuária - CNPMS (Centro Nacional de Pesquisa de Milho e Sorgo), Sete Lagoas-MG;

${ }^{3}$ Programa de Biotecnologia Aplicada à Agricultura - Universidade Paranaense. Praça Mascarenhas de Moraes, 4282 - Centro * autor para correspondência: Luzia Doretto Paccola Meirelles (luziadoretto@prof.unipar.br).
} 


\section{LA ACTIVIDAD DE NUCLEACIÓN DE HIELO Y LA DENSIDAD DE POBLACIÓN DEL PATÓGENO PUEDEN SER FACTORES QUE CONTRIBUYEN AL PROGRESO DE LA ENFERMEDAD MANCHA BLANCA DEL MAÍZ}

RESUMEN: La mancha blanca del maíz es una enfermedad de la hoja que ha causado pérdidas considerables, tanto cualitativas como cuantitativas para la producción de maíz. Su agente etiológico, Pantoea ananatis, es una bacteria epífita, Gram-negativa, formadora de colonias amarillas, capaz de causar hielo, incluso en ambientes tropicales a temperaturas donde esto normalmente no ocurre (actividad de nucleación de hielo - INA). Este estudio tuvo como objetivo caracterizar los aislados de $P$. ananatis en términos de actividad de INA y evaluar el efecto de la densidad bacteriana en la expresión del fenotipo de INA y en el proceso de desarrollo de la enfermedad. El patógeno se aisló de las lesiones iniciales de la enfermedad, las anasarcas, y se evaluó la expresión del fenotipo INA en diferentes concentraciones bacterianas. Lo mismo se hizo con aislamientos epifitos obtenidos de la superficie de la hoja de plantas de maíz sanas. De los 24 aislados bacterianos estudiados, solo 13 presentaron el fenotipo INA+. La expresión de este fenotipo depende de la densidad celular. Se inocularon aislamientos INA+ e INA- en hojas desprendidas y en plantas del cultivar HS200 en el campo, en diferentes concentraciones del inóculo. Ninguno aislado INA- reprodujo síntomas en el laboratorio. De los cinco aislamientos de INA+, solo uno de ellos reprodujo síntomas en el laboratorio. En el campo, el aislado INA+ pudo promover lesiones en todas las concentraciones evaluadas. Se concluye que la nucleación de hielo por $P$. ananatis depende de la cepa y la densidad bacteriana, y este fenómeno puede estar involucrado en el desarrollo de los síntomas de la enfermedad de la mancha blanca del maíz.

PALABRAS CLAVE: INA. Pantoea ananatis. Phaeosphaeria maydis. Zea mays.

\section{Introdução}

A partir da década de 90, a incidência e a severidade das doenças do milho contribuíram para uma sensível redução na produtividade deste cereal. Entre essas doenças uma de destaque é a Mancha Branca do Milho (MBM) (Figura 1). Esta doença instalou-se no Brasil na década de 80 e sua incidência e severidade aumentaram significativamente a partir dos anos 90 (FERNANDES; OLIVEIRA, 2000) e a partir de 2010 os danos causados pela doença aumentaram drasticamente (CUSTÓDIO et al., 2020).

Atualmente a MBM tem sido considerada uma das doenças mais agressivas do milho, sendo encontrada em todas as regiões produtoras do país com ocorrência em outros países da América do Sul, América Central, África e Ásia (COSTA; SILVA; COTA, 2017). As perdas de produção podem chegar a 60\% (GODOY et al., 2001; SYNGENTA, 2019). A incidência da doença aumenta em condições de alta umidade relativa e temperaturas moderadas e estas condições ocorrem com frequência durante o período de cultivo do milho em várias regiões do Brasil (FANTIM, 1994).

O estágio inicial da doença é marcado pela presença, nas folhas, de lesões aquosas, verde-escuras, do tipo anasarca que posteriormente tornam-se necróticas, de cor palha. O número de lesões foliares pode variar dependendo da cultivar (PACCOLA-MEIRELLES et al., 1998), podendo ser circular a elíptica, com diâmetro variando de 0,3 a $1 \mathrm{~cm}$ (FERNANDES; OLIVEIRA, 2000). Em condições favoráveis, a doença causa sérios danos ao processo de enchimento de grãos levando a seca prematura da planta, com redução do ciclo e quedas acentuadas no tamanho e massa dos grãos. Paccola-Meirelles et al. (2001) isolaram, a partir de lesões em estágios iniciais da doença, uma bactéria Gram-negativa formadora de colônia de coloração amarela brilhante que, quando reinoculada em plantas de milho sob condições controladas, reproduziu sintomas semelhantes aos do campo. O agente etiológico da doença foi identificado como Pantoea ananatis (PACCOLA-MEIRELLES et al., 2001; GONÇALVES et al., 2013). P. ananatis foi descrita por Serrano (1928) como Erwinia ananas (synonym, Erwinia uredovora) e Mergaert et al. (1993) a transferiram para o gênero Pantoea, como P. ananas. Posteriormente Trüper e De'Clari (1997) corrigiram para P.ananatis.

A bactéria reside epifiticamente nas folhas de milho (ESCANFERLA et al., 2018) e pode alcançar os espaços intercelulares da epiderme foliar através de aberturas naturais como estômatos ou injúrias foliares (BOMFETI et al., 2008). Segundo Sauer et al. (2014) e Sauer et al. (2015), este patógeno tem a capacidade de induzir a formação de cristais de gelo em temperaturas onde normalmente isto não ocorreria, nucleação de gelo (ice nucleation activity - INA) (MAKI et al., 1974), que pode levar à formação de lesões foliares (ROMEIRO, 2001) e consequentemente promover danos importantes economicamente (KAWAHARA, 2002). Considerando a importância da doença e a falta de conhecimentos sobre a biologia do seu agente etiológico, este estudo teve como objetivo caracterizar diferentes isolados de $P$. ananatis quanto à atividade INA+ e avaliar o efeito da concentração de bactérias no processo de nucleação do gelo e na reprodução dos sintomas da doença.

\section{Materiais e Métodos}

\section{Isolamento da bactéria a partir de plantas de milho infec- tadas a campo}

Folhas de milho doentes contendo lesões do tipo anasarcas (Fig. 1) foram coletadas a campo e lavadas com sabão neutro.

O protocolo de isolamento seguiu aquele descrito por Paccola-Meirelles et al. (2001). As lesões anasarcas (Fig. 1) foram retiradas das folhas com auxílio de um bisturi, desinfestadas em álcool etílico $70 \%$ (um minuto), cloramina $\mathrm{T}$ $0,25 \%$ (quatro minutos) e lavadas três vezes em água destilada esterilizada (um minuto para cada lavagem). A água da última lavada foi plaqueada em meio TSA (Triptic Soy Agar) para controle da metodologia de desinfecção. Com auxílio de um bisturi esterilizado foram retiradas e descartadas as bordas de cada segmento foliar e segmentos de um milímetro foram retirados da extremidade das lesões e transferidos para meio TSA. 
Figura 1: Folha de milho atacada pela doença MBM. Os círculos indicam lesões em estágio inicial da doença, as lesões anasarcas. Os retângulos indicam lesões necróticas, secas e de coloração palha.

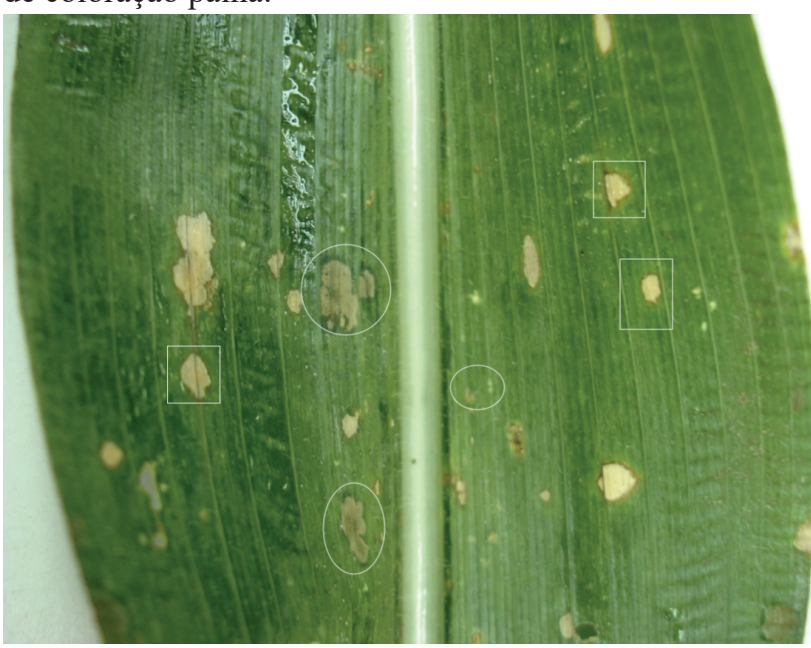

Arquivo pessoal, 2018

Após incubação em estufa a $30^{\circ} \mathrm{C} \pm 2^{\circ} \mathrm{C}$, as bactérias foram isoladas, purificadas em meio TSA e transferidas para meio de cultura Agar MacConkey afim de selecionar as bactérias Gram-negativas e fermentadoras de Lactose (Lac+). A identidade dos isolados foi verificada pela amplificação de primers específicos para $P$. ananatis (FIGUEIREDO; PACCOLA-MEIRELLES, 2012). Após confirmação, os isolados foram mantidos em meio TSA.

\section{Avaliação da atividade de nucleação de gelo (Ice Nuclea- tion Activity - INA) nos isolados bacterianos}

Os isolados bacterianos foram inoculados em 5,0 $\mathrm{mL}$ de Tryptic Soy Broth (TSB) e incubados sob agitação a $30^{\circ} \mathrm{C}$ por um período de $24 \mathrm{~h}$ à $60 \mathrm{rpm}$. Após esse período retirou-se $1,0 \mathrm{~mL}$ de cada cultura para os testes INA. O restante foi centrifugado a $3.500 \mathrm{~g}$ por 15 minutos e separado o sobrenadante. Ao pellet foram adicionados $2,0 \mathrm{~mL}$ de água ultrapurificada e agitado em agitador de tubos. Esta suspensão foi submetida a diluições seriadas em água ultrapurificada, e plaqueadas em meio TSA para estimar o número de Unidades Formadoras de Colônia (UFC). As suspensões diluídas a $10^{-1}, 10^{-2}, 10^{-3}$ e $10^{-4}$ foram agitadas em agitador de tubo individual e avaliadas quanto a atividade de INA.

Tubos de ensaio contendo $1,0 \mathrm{~mL}$ de água ultrapurificada esterilizada foram mantidos em banho de gelo a temperaturas abaixo de $-5^{\circ} \mathrm{C}$ por dois minutos. Logo em seguida eles receberam $100 \mu \mathrm{L}$ de cada suspensão bacteriana. A formação imediata de gelo no tubo de ensaio revelou o fenótipo INA+ do isolado.

Foram feitos dois controles nas mesmas condições do experimento, um com meio TSB, livre de bactérias e diluídos em água ultrapurificada quando necessário, e o outro controle apenas com água ultrapurificada. Os mesmos testes foram feitos também com os sobrenadantes das culturas.

\section{Teste de patogenicidade a campo e em laboratório Preparo do inóculo}

Um pré-inóculo foi preparado cultivando-se cada isolado em meio TSB por horas 12 horas sob agitação (60 $\mathrm{rpm}$ ) a $30^{\circ} \mathrm{C}$. Após este período, $1,0 \mathrm{~mL}$ do pré inóculo foi transferido para $100 \mathrm{~mL}$ de meio TSB e incubado nas mesmas condições anteriores durante quatro horas. Para o preparo dos inóculos, foi acrescida a essa a cultura bacteriana uma solução salina $0,85 \%$ na proporção de $1: 1$ (inóculo sem diluição) e, em seguida, a suspensão foi submetida a diluições seriadas, $10^{-1}, 10^{-2}, 10^{-3} \mathrm{e} 10^{-4}$, também em solução salina $0,85 \%$ (inóculos diluídos). Estimou-se o número de UFC em meio TSA.

Como controle, foram utilizados, o meio TSB, o meio TSB diluído em solução salina e a solução salina pura, todos sem bactérias. Os inóculos controles foram submetidos aos mesmos procedimentos dos tratamentos. Tanto os controles, como os inóculos sem diluição e os diluídos foram mantidos a $4^{\circ} \mathrm{C}$ por duas horas antes de serem empregados nos testes de patogenicidade.

\section{Testes e patogenicidade a campo}

Plantas da cultivar HS200 suscetível à MBM, com 60 dias de idade, foram utilizadas nos testes de patogenicidade a campo. As folhas foram injuriadas previamente com uma esponja macia e pulverizadas com os inóculos controle, os diluídos e os inóculos não diluídos. Uma câmara plástica foi colocada sobre o experimento por um período de 72 horas. Após este período, observações diárias foram efetuadas para avaliar o aparecimento de lesões. Foram realizadas cinco repetições por tratamento.

\section{Testes de patogenicidade em laboratório}

Folhas da porção mediana de plantas de milho com 60 dias de idade, cultivar HS200, foram destacadas da planta, lavadas com sabão neutro, cortadas e acondicionadas em câmaras de microumidade (CM) (BERGSTROM; NICHOLSON, 1983) conforme apresentado na Figura 2. Na altura de cada poço a folha foi suavemente injuriada com uma microagulha e inoculada com $50 \mu \mathrm{L}$ de inóculo. Também foi feito um controle apenas com as folhas injuriadas. As CM foram acondicionadas em câmaras úmidas por 72 h. As CM foram retiradas das folhas e monitoradas diariamente para avaliar o aparecimento das lesões. Foram realizadas cinco repetições por tratamento.

Figura 2: Segmento foliar de milho, cultivar HS200, acondicionado em câmara de microumidade, contendo 12 poços de $0,3 \mathrm{~cm}$ de diâmetro, antes de ser inoculado em laboratório com as suspensões bacterianas.

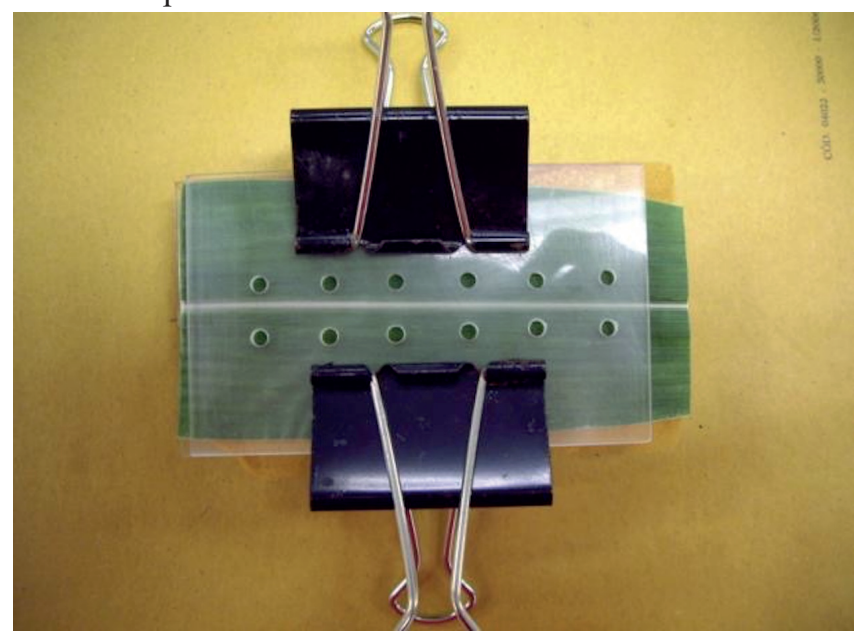




\section{Resultados e Discussão}

\section{Isolamento da bactéria a partir de plantas de milho infec- tadas a campo}

Os isolados bacterianos apresentaram morfologia semelhante à $P$. ananatis, com colônias mucoides de coloração amarela brilhante (Fig. 3) e, quando transferidos para meio Agar MacConkey, mostraram crescimento positivo. $\mathrm{O}$ meio Agar MacConkey (MACCONKEY, 1905) contém em sua composição, ácido biliar, cristal violeta, vermelho neutro e lactose. $\mathrm{O}$ ácido biliar e o cristal violeta inibem o crescimento da maioria das bactérias Gram-positivas e o vermelho neutro cora as bactérias fermentadoras de lactose. Assim, foi possível diferenciar as bactérias fermentadoras de lactose $(\mathrm{Lac}+)$ (colônias vermelhas a rosa) daquelas não fermentadoras de lactose (Lac-) (colônias transparentes a incolores). Os isolados bacterianos que cresceram em meio Agar MacConkey, comprovaram ser bactérias Gram-negativas e fermentadoras de lactose, em concordância com a descrição feita por Paccola-Meirelles et al. (2001) para a bactéria $P$. ananatis isoladas da MBM. As posteriores análises moleculares desses isolados com os primers ANAF e EC5, específicos para P. ananatis da MBM (FIGUEIREDO; PACCOLA-MEIRELLES, 2012), confirmaram a identidade da bactéria. $P$. ananatis foi isolada em uma frequência de $62,2 \%$ das lesões obtidas a campo. Os isolados bacterianos selecionados para este estudo encontram-se listados na Tabela 1.

Figura 3: Placa contendo meio TSA para isolamento da bactéria Pantoea ananatis a partir de segmentos de lesões iniciais da mancha branca do milho, as lesões anasarcas. Pode ser observado que a maioria dos segmentos apresentou crescimento de uma bactéria de coloração amarelo brilhante compatível com a morfologia de $P$. ananatis.

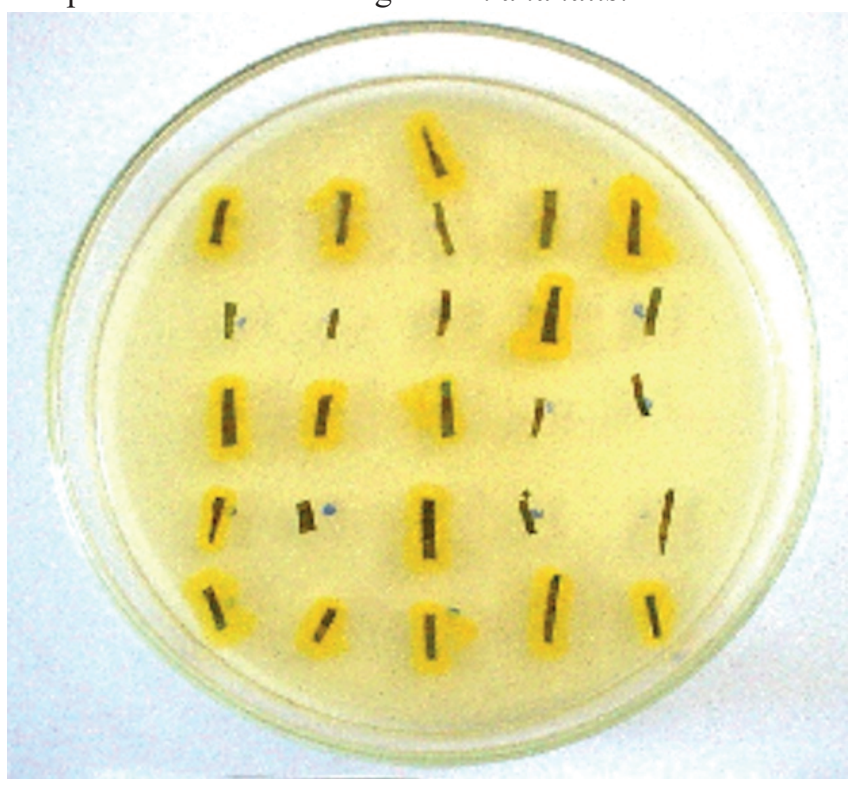

Tabela 1: Isolados da bactéria Pantoea ananatis utilizados neste estudo.

\begin{tabular}{|c|c|}
\hline Isolados & Local de Isolamento \\
\hline $\mathrm{B} 2 *$ & Londrina/PR \\
\hline $\mathrm{K} 1 *$ & Londrina/PR \\
\hline $\mathrm{K} 3 *$ & Londrina/PR \\
\hline WT2* & Distrito da Warta- Londrina-PR \\
\hline WT8* & Distrito da Warta- Londrina-PR \\
\hline WT9* & Distrito da Warta- Londrina-PR \\
\hline WT11* & Distrito da Warta- Londrina-PR \\
\hline WT14* & Distrito da Warta- Londrina-PR \\
\hline MG2* & Ponta Porã - MS \\
\hline MG4* & Ponta Porã - MS \\
\hline $\mathrm{MP} 1 * *$ & Ponta Porã - MS \\
\hline $\mathrm{MP5} * *$ & Ponta Porã - MS \\
\hline MP6** & Ponta Porã - MS \\
\hline EMS05* & Sete Lagoas-MG \\
\hline $\mathrm{F} 5 *$ & Sete Lagoas-MG \\
\hline $\mathrm{F}^{*}$ & Sete Lagoas-MG \\
\hline $\mathrm{F} 7 *$ & Sete Lagoas-MG \\
\hline $\mathrm{F} 8 *$ & Sete Lagoas-MG \\
\hline $\mathrm{EM} 2 * * *$ & Londrina - PR \\
\hline $\mathrm{EM} 4 * * *$ & Londrina - PR \\
\hline $\mathrm{EM} 5 * * *$ & Londrina - PR \\
\hline EM6*** & Londrina - PR \\
\hline $\mathrm{EM} 7 * * *$ & Londrina $-\mathrm{PR}$ \\
\hline EM9*** & Londrina - PR \\
\hline
\end{tabular}

*Isolados a partir de lesões anasarcas da MBM

** Isolados a partir de lesões anasarcas da MBM de milho pipoca *** Isolados epifíticos foliares (isolados previamente por Escanferla et al., 2018)

Atividade de nucleação do gelo pelos isolados bacterianos.

O teste de nucleação do gelo revelou que a maioria dos isolados foram INA+ (Tabela 2). No entanto, foi possível observar que essa capacidade de nucleação de gelo é dependente da concentração de células na suspensão bacteriana (Tabela 2). Todos os isolados epifíticos foram portadores do fenótipo INA + . A concentração celular de $10^{6} \mathrm{UFC} / \mathrm{mL}$ foi suficiente para o isolado EM7 catalisar a formação do gelo, enquanto que outros, mesmo em concentração celular alta não expressaram o fenótipo (Tabela 2). Provavelmente a expressão desse caráter é dependente de outros fatores, além da concentração celular. Uma variabilidade pode ser observada entre aos isolados em relação a esta característica. Os sobrenadantes das culturas não apresentaram atividade INA+, indicando que o fator responsável por essa característica ou não está sendo liberado no meio de cultivo ou a metodologia utilizada não permitiu isolar esses agentes em quantidades suficientes para a ocorrência do fenômeno. (Tabela 2)

Em concentrações celulares mais altas, a nucleação do gelo ocorreu com maior frequência (Tabela 2). Resultados semelhantes foram obtidos por Maki et al. (1974) com a 
bactéria Pseudomonas syringae, isolada de folhas decíduas de Alnus tenuifolia. Esta bactéria apresentou atividade de nucleação de gelo somente nas concentrações de $10^{7}$ e $10^{8}$ células/mL de meio de cultivo.

Tabela 2: Atividade de nucleação de gelo em isolados de Pantoea ananatis de milho.

\begin{tabular}{|c|c|c|c|c|c|c|}
\hline \multirow[t]{2}{*}{ Isolados } & \multirow{2}{*}{$\begin{array}{c}\mathrm{UFC} / \mathbf{m L} \\
\text { inicial }\end{array}$} & \multicolumn{5}{|c|}{ INA } \\
\hline & & SD & $10^{-1}$ & $10^{-2}$ & $10^{-3}$ & $10^{-4}$ \\
\hline $\mathrm{K} 1 *$ & $1,20 \times 10^{10}$ & + & + & - & - & - \\
\hline $\mathrm{K} 3 *$ & $2,11 \times 10^{10}$ & + & - & - & - & - \\
\hline WT2* & $2,75 \times 1^{09}$ & + & + & - & - & - \\
\hline WT8* & $3,26 \times 1^{09}$ & - & - & - & - & - \\
\hline WT9* & $4,08 \times 1^{09}$ & - & - & - & - & - \\
\hline WT11* & $1,19 \times 10^{11}$ & + & - & - & - & - \\
\hline WT14* & $5,15 \times 10^{12}$ & - & - & - & - & - \\
\hline $\mathrm{B} 2 *$ & $5,20 \times 1^{09}$ & + & - & - & - & - \\
\hline EMS05* & $5,33 \times 1^{09}$ & + & - & - & - & - \\
\hline $\mathrm{F}^{*}$ & $5,82 \times 10^{12}$ & - & - & - & - & - \\
\hline $\mathrm{F} 6 *$ & $6,21 \times 10^{10}$ & - & - & - & - & - \\
\hline F7* & $2,49 \times 10^{10}$ & + & + & - & - & - \\
\hline $\mathrm{F} 8 *$ & $3,11 \times 10^{12}$ & - & - & - & - & - \\
\hline MG2* & $5,25 \times 10^{12}$ & - & - & - & - & - \\
\hline MG4* & $5,89 \times 10^{12}$ & - & - & - & - & - \\
\hline $\mathrm{MP} 1 * *$ & $5,51 \times 10^{10}$ & - & - & - & - & - \\
\hline MP5** & $6,9 \times 10^{12}$ & - & - & - & - & - \\
\hline MP6** & $6,38 \times 10^{10}$ & - & - & - & - & - \\
\hline $\mathrm{EM} 2 * * *$ & $7,50 \times 1^{07}$ & + & - & - & - & - \\
\hline $\mathrm{EM} 4 * * *$ & $1,27 \times 1^{08}$ & + & + & - & - & - \\
\hline EM5*** & $3,13 \times 1^{09}$ & + & - & - & - & - \\
\hline EM6*** & $1,20 \times 10^{10}$ & + & - & - & - & - \\
\hline EM7*** & $1,50 \times 1^{09}$ & + & + & + & + & - \\
\hline EM9*** & $>10^{12}$ & + & + & - & - & - \\
\hline $\begin{array}{l}\text { Controle } \\
\text { TSB }\end{array}$ & - & - & - & - & - & - \\
\hline $\begin{array}{l}\text { Controle } \\
\mathrm{H} 2 \mathrm{O}\end{array}$ & - & - & - & - & - & - \\
\hline Sobrenadante & - & - & - & - & - & - \\
\hline
\end{tabular}

UFC: Unidades Formadoras de Colônias

INA: Ice nucleation activity

SD: sem diluição

*Isolados a partir de lesões anasarcas da MBM

** Isolados a partir de lesões anasarcas da MBM de milho pipoca

*** Isolados epifíticos foliares. (isolados previamente por Escanferla et al., 2018).

A nucleação do gelo foi descrita também em bactérias do gênero Pseudomonas, Pantoea e Xanthomonas (LINDOW; ANDERSEN, 1996; MAKI et al., 1974; TURNER et al., 1991) causando sérios danos ao hospedeiro. De acordo com Lindow (1983), a ocorrência do processo nucleação de gelo depende da capacidade da bactéria em produzir os nucleantes de gelo ativos e também da concentração de bacté- rias INA+ no local e, quanto maior o número de nucleantes de gelo ativos, maior será a eficiência do processo (HIRANO; UPPER, 2000).

Sauer et al. (2014) sugeriram que a atividade INA do patógeno da MBM, P. ananatis, quando em condições ambientais adequadas, pode levar à formação desses cristais de gelo nos espaços intercelulares da epiderme foliar, ocasionando a ruptura da parede celular do tecido infectado. Quando isso ocorre, a membrana celular se rompe causando uma desorganização tecidual e a formação da lesão encharcada, a anasarca, que mais tarde torna-se necrótica e de coloração palha devido à morte do tecido local por congelamento (ROMEIRO, 2001). Essa desorganização celular nas lesões da MBM foi demonstrada anteriormente por Bomfeti et al. (2008) por microscopia óptica e eletrônica. Escanferla et al. (2018) também encontraram $P$. ananatis INA+ sobrevivendo epifiticamente na folha de milho e observaram um aumento gradual na sua população com a idade da planta. Em cultivares susceptíveis, o aumento da população de $P$. ananatis, associado com a umidade relativa do ar e quedas de temperatura, são determinantes para o aparecimento das lesões (WYSMIERSKI; REAL; PACCOLA-MEIRELLES, 2006).

Todos os isolados epifíticos aqui estudados catalisaram a formação de gelo, em concordância com os estudos de Sauer et al. (2014) e Escanferla et al. (2018), confirmando que o processo de produção de gelo por esse agente etiológico somente ocorre quando a população bacteriana se encontra em nível mais elevado.

Os resultados apresentados na Tabela 2 demonstram que a capacidade de nucleação do gelo por $P$. ananatis isolada da MBM é dependente não só do isolado, mas também da sua concentração celular.

\section{Teste de patogenicidade em laboratório e a campo}

Os isolados caracterizados fenotipicamente como INA+, K1, K3, EMS05, WT2, EM7 e os INA-, WT8, WT14, foram selecionados para os testes de patogenicidade nas CM em laboratório (Tabela 3). Os isolados WT2 (INA+) e WT8 (INA-) foram selecionados para os testes de patogenicidade a campo (Tabela 4$)$.

O isolado WT2 foi o único que reproduziu sintomas quando inoculado nas folhas de milho em CM (Tabela 3). Este isolado foi capaz de desenvolver lesões somente na concentração de $10^{9} \mathrm{UFC} / \mathrm{mL}$ (Tabela 3 e Fig. 4). Os demais isolados não reproduziram sintomas da doença. Nenhuma lesão foi observada nos tratamentos controles (Tabela 3). 
Tabela 3: Teste de patogenicidade dos isolados de $P$. ananatis em folhas destacadas de milho da cultivar HS200 em câmaras de microumidade (CM).

\begin{tabular}{lccccc}
\hline Isolados & UFC/mL & SD & \multicolumn{3}{c}{ Diluição } \\
& & & $\mathbf{1 0}^{-1}$ & $\mathbf{1 0}^{-2}$ & $\mathbf{1 0}^{-3}$ \\
\hline K1 (INA+) & $7,910^{12}$ & - & - & - & - \\
K3 (INA+) & $4,510^{10}$ & - & - & - & - \\
EMS05 (INA+) & $5,310^{11}$ & - & - & - & - \\
WT2 (INA+) & $6,81^{09}$ & ++ & - & - & - \\
WT8 (INA-) & $8,51^{09}$ & - & - & - & - \\
EM7 (INA+) & $1,11^{08}$ & - & - & - & - \\
WT14 (INA-) & $6,310^{12}$ & - & - & - & - \\
\hline
\end{tabular}

\section{Controles:}

Solução salina

TSA+Solução salina

TSA

UFC: Unidades Formadoras de Colônia

SD: Sem Diluição

$+=$ sintoma positivo

- = sintoma negativo

Figura 4: Isolado WT2 (INA+) de Pantoea ananatis de lesões da MBM, inoculado em segmentos foliares da cultivar HS200 (60 dias de idade) em CM, nas concentrações de 107\%, $10^{8}$ e $10^{9} \mathrm{UFC} / \mathrm{mL}$. Pode ser observado que apenas o tratamento contendo suspensão bacteriana na concentração de $10^{9}$ $\mathrm{UFC} / \mathrm{mL}$ reproduziu lesões foliares. Nas demais concentrações e no controle não foram observadas o desenvolvimento de lesões.

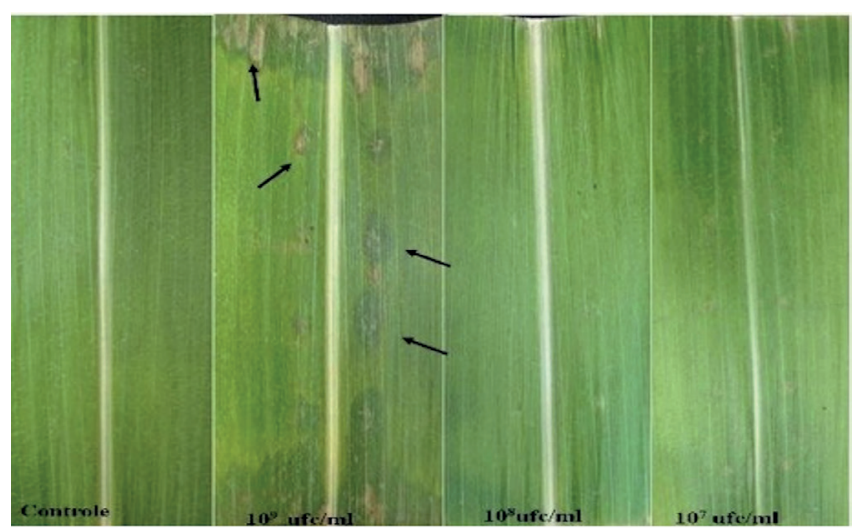

Tabela 4: Teste de patogenicidade dos isolados de Pantoea ananatis em plantas de milho da cultivar HS200 á campo.

\begin{tabular}{lcccc}
\hline Linhagens & UFC/mL & \multicolumn{3}{c}{ Diluições } \\
\hline & & SD & $\mathbf{1 0}^{8}$ & $\mathbf{1 0}^{7}$ \\
\cline { 3 - 5 } WT2 & 6,8109 & ++ & ++ & + \\
WT8 & 8,5109 & - & - & - \\
\hline
\end{tabular}

Controles:

Solução salina

TSA+Solução salina

TSA

UFC: Unidades Formadoras de Colônia

SD: Sem Diluição

$+=$ sintoma positivo

- = sintoma negativo
O isolado WT2 (INA+) reproduziu sintomas da MBM a campo, nas três concentrações empregadas (Tabela 4; Fig. 5). Uma leve queima foliar pôde ser observada no inóculo mais concentrado, $10^{9} \mathrm{UFC} / \mathrm{mL}$.

Como no experimento de laboratório, o isolado WT8 (INA-) também não reproduziu os sintomas da MBM a campo (Tabela 3 e 4).

Nenhuma lesão foi observada nos tratamentos controles a campo.

Figura 5: Isolado WT2 (INA+) de Pantoea ananatis inoculado a campo em plantas de milho da cultivar HS200 com 60 dias de idade, nas concentrações de $10^{7}, 10^{8}$ e $10^{9} \mathrm{UFC/}$ $\mathrm{mL}$. Lesões foram desenvolvidas em todas as concentrações bacterianas avaliadas, porém na concentração de $10^{9} \mathrm{UFC} /$ $\mathrm{mL}$, ocorreu queima foliar.

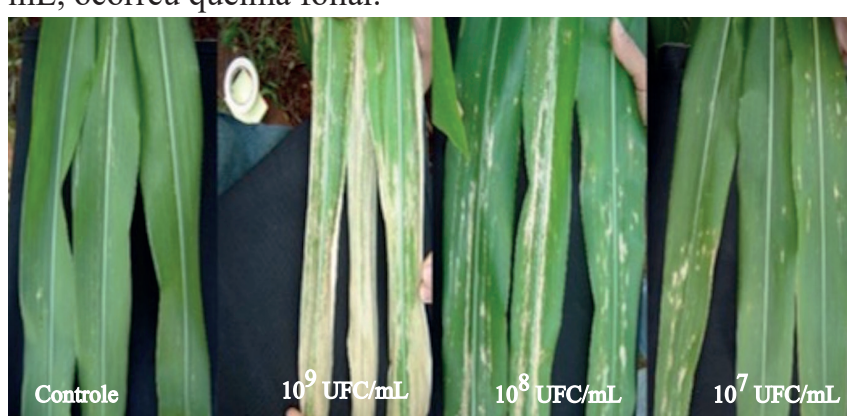

Wysmierski et al. (2006) observaram o aparecimento dos sintomas somente após um pronunciado aumento da população epifítica de $P$. ananatis sobre as folhas de milho. Os resultados obtidos a campo e em condições controladas no laboratório, comprovaram os resultados de Wysmierski et al. (2006). Lindow (1987), estudando a doença Mancha Marrom de feijão, causada por Pseudomonas syringae pv. syringae, observando um aumento na incidência da doença proporcionalmente ao aumento da população epifítica deste patógeno em folhas de feijão. Em estudos anteriores Lindow, Arny e Upper (1978) avaliando o efeito da pulverização da bactéria INA+, Erwinia herbicola, em folhas de milho, observaram um aumento nos danos provocados por esse patógeno conforme se aumentava a concentração das células bacterianas do inóculo.

Os resultados do presente estudo demonstram que nem todos os isolados de $P$. ananatis possuem a capacidade de produzir gelo nas condições em que foi realizado o experimento. Há uma indicação de que a capacidade de nucleação, associada à densidade populacional bacteriana são fatores que colaboram para o desenvolvimento dos sintomas da MBM em folhas de milho, porém novos testes envolvendo um número maior de isolados INA+ e INA- devem ser efetuados para comprovar essa hipótese.

\section{Conclusão}

Conclui-se que a atividade de nucleação de gelo é dependente da linhagem, uma vez que nem todos os isolados expressaram o fenótipo $\mathrm{INA}^{+}$quando submetidos ao mesmo tratamento, demonstrando a ocorrência de variabilidade genética para este caráter entre os isolados estudados. A concentração de células bacterianas é também um fator de importância na expressão do fenótipo INA por P. ananatis, 
sendo dependente da linhagem e da densidade populacional para se expressar.

\section{Referências}

BERGSTROM, G. C.; NICHOLSON, R. I. Microhumidity chamber for quantitative inoculation of attached corn leaves with fungal pathogens. Phytopathology, v. 73, n. 7, p. 10401042, 1983.

BOMFETI, C. A. et al. Localization of Pantoea ananatis inside lesions of maize white spot disease using transmission electron microscopy and molecular techniques. Tropical Plant Pathology, Brasília, v. 33, n. 1, p. 63-66, 2008.

COSTA, R. V.; SILVA, D. D.; COTA, L. V. Evolução dos sintomas da mancha-branca no campo. Sete Lagoas, 2017. Circular Técnica, n. 229, EMBRAPA, 5 p.

CUSTÓDIO, A. A. P. et al. Eficiência de fungicidas no controle da mancha branca do milho - segunda safra 2018 e 2019. Londrina, 2019. Boletim Técnico, n. 94, IAPAR, 34 p.

ESCANFERLA, M. E. et al. Viability and dissemination of Pantoea ananatis, etiological agent of maize white spot disease. Agronomy Science and Biotechnology, v. 4, n. 2, p. 52-58, 2018.

FERNANDES, F. T.; OLIVEIRA, E. Principais doenças na cultura do milho. Sete Lagoas, 2000. Circular Técnica, n. 26, EMBRAPA, 80 p.

FANTIM, G. M. Mancha de Phaeosphaeria, doença do milho que vem aumentando sua importância. Biológico, São Paulo, v. 56, n. 1/2, p. 39, 1994.

FIGUEIREDO, J. E. F.; PACCOLA-MEIRELLES, L. D. Simple, rapid e accurate PCR-based detection of Pantoea ananatis in maize, sorghum and Digitaria sp. Journal of Plant Pathology, v. 94, n. 3, p. 663-667, 2012.

GODOY, C. V.; AMORIM, L.; BERGAMIN FILHO, A. Alterações na fotossíntese e na transpiração de folhas de milho infectadas por Phaeosphaeria maydis. Fitopatologia Brasileira, Brasília, v. 26, n. 2, p. 209-215, 2001.

GONÇALVES, R. M. et al. Etiology of phaeosphaeria leaf spot disease of maize. Journal of Plant Pathology, v. 95, n. 3, p. 559-569, 2013.

HIRANO, S. S.; UPPER, C. D. Bacteria in the leaf ecosystem with emphasis on Pseudomonas syringae - a pathogen, ice nucleus, and epiphyte. Microbiology and Molecular Biology Reviews, v. 64, n. 3, p. 624-653, 2000.

LINDOW, S. E. The role of bacterial ice nucleation in frost injury to plants. Annual Review of Phytopathology, California, v. 21, p. 363-384, 1983.

LINDOW, S. E. Competitive exclusion of epiphytic bacteria by ice-Pseudomonas syringae mutants. Applied and Environmental Microbiology, v. 53, n. 10, p. 2520-2527, 1987.

LINDOW, S. E.; ARNY, D. C.; UPPER C. D. Erwinia herbicola: a bacterial ice nucleus active in increasing frost injury to corn. Phytopathology, v. 68, p. 523-527, 1978.

LINDOW, S. E.; ANDERSEN, G. L. Influence of immigration on epiphytic bacterial populations on navel orange leaves. Applied and Environmental Microbiology, v. 62, n. 8, p. 2978-2987, 1996.

MACCONKEY, A. T. Lactose-fermenting bacteria in faeces. The Journal of Hygiene, v. 5, n. 3, p. 333-379, 1905.

MAKI, L. R. et al. Ice nucleation induced by Pseudomonas syringae. Applied Microbiology, v. 28, n. 3, p. 456-459, 1974.

MERGAERT, J.; VERDONCK, L.; KERSTERS, K. Transfer of Erwinia ananas (synonym, Erwinia uredovora) and Erwinia stewartii to the Genus Pantoea emend. as Pantoea ananas (Serrano 1928) comb. nov. and Pantoea stewartii (Smith 1898) comb. nov., respectively, and description of Pantoea stewartii subsp. indologenes subsp. nov. International Journal of Systematic Bacteriology, v. 43, n. 1, p. 162-173, 1993.

PACCOLA-MEIRELLES, L. D. et al. Avaliação da expressão da resistência para mancha foliar de Phaeosphaeria em milho (Zea mays) quanto ao número e tamanho de lesões. In: CONGRESSO NACIONAL DE MILHO E SORGO, 22. 1998, Sete Lagoas. Anais [...] Sete Lagoas: SBMS, 1998. CD-ROM.

PACCOLA-MEIRELLES, L. D. et al. Detection of a bacterium associated with a leaf spot disease of maize in Brazil. Journal of Phytopatology, v. 149, n. 5, p. 275-279, 2001.

ROMEIRO, R. S. Métodos em bacteriologia de plantas. Imprensa Universitária. Viçosa: UFV, 2001. 280p.

SAUER, A. V. et al. Ice nucleation activity in Pantoea ananatis obtained from maize white spot lesions. Semina: Ciências Agrárias, v. 35, n. 4, p. 1659-1666, 2014.

SAUER, A. V. et al. Survival of Pantoea ananatis, causal agent of maize white spot disease in crop debris. Agronomy Science and Biotechnology, v. 1, n. 1, p. 21- 24, 2015.

SERRANO, F. B. Bacterial fruitlet brown-rot of pineapple in the Philippines. Philippine Journal Science, v. 36, n. 3, p. 271-324, 1928.

SYNGENTA. Conheça a duas principais doenças do milho e como proteger sua lavoura. Disponível em: https:// portalsyngenta.com.br/noticias/conheca-as-duas-principaisdoencas-do-milho. Acesso em: 20 mar. 2020. 
TURNER, M. A.; AREllanO, F.; KOZlOFF, L. M. Components of ice nucleation structures of bacteria. Journal of Bacteriology, v. 173, n. 20, p. 6515-6527, 1991.

TRÜPER, H. G.; DE'CLARI, L. Taxonomic note: necessary correction of specific epithets formed as substantives (nouns) 'in apposition'. International Journal of Systematic Bacteriology, 47, n. 3, p. 908-909, 1997.

WYSMIERSKI, P. I.; REAL, K. R.; PACCOLAMEIRELLES, L. D. Pantoea ananatis: monitoramento da população epifítica sobre folhas de milho e avaliação de métodos artificiais de inoculação. In: CONGRESSO NACIONAL DE MILHO E SORGO, SIMPÓSIO BRASILEIRO SOBRE A LAGARTA DO CARTUCHO, SIMPÓSIO SOBRE Colletotrichum graminicola, 26., 2., 1., 2006, Belo Horizonte. Anais... Belo Horizonte: SBMS, 2006. CD ROM.

Recebido em: 01.11.2019

Aceito em: 28.12.2019 